\title{
Agrotóxicos: os venenos ocultos na nossa mesa
}

\author{
Maria Tereza Borges Araujo Frota 1,2 \\ Carlos Eduardo Siqueira 2
}

doi:10.1590/0102-311X00004321

Estudos sobre o controle de resíduos de agrotóxicos no Brasil colocam em pauta um importante problema de saúde pública no país, decorrente dos contextos social, político e econômico em que está inserido. Desde 2008 o Brasil é o maior consumidor de agrotóxicos no mundo ${ }^{1}$. Refém de um sistema de produção agrária de alimentos totalmente dependente do uso desses produtos, estima-se que o brasileiro consome, em média, $7 \mathrm{~kg}$ de agrotóxicos por ano 2 . Esse consumo torna-se particularmente preocupante se considerarmos o impacto que gera na saúde individual e coletiva, amplamente descrito na literatura 3 .

Pesquisas realizadas nas últimas décadas revelam que os agrotóxicos afetam negativamente a saúde dos consumidores 4,5, trabalhadores 6,7,8 e lactentes contaminados pelo leite materno 3,9,10. Esses agravos representam um aumento na demanda dos serviços públicos de saúde como consequência de intoxicações agudas e doenças crônicas relacionadas aos efeitos deletérios dos agrotóxicos. Dados do Sistema de Informação de Agravos de Notificação (SINAN) indicam que o uso de agrotóxicos e as intoxicações deles derivadas aumentaram de 2007 a 2016, ocupando o segundo lugar entre as intoxicações exógenas e a primeira posição em letalidade 11. Além disso, impactam negativamente no meio ambiente, por meio da contaminação do solo e mananciais de água e da eliminação de espécies e plantas nativas 5,12 .

Na contramão dessas evidências, o governo brasileiro vem cedendo à pressão da indústria agroquímica multinacional por meio de ações como isenções de impostos, paralisação dos processos de fiscalização das indústrias e flexibilização das regras para o uso de agrotóxicos no país. Exemplo disso foi a liberação de 474 novos produtos só no ano de 2019 13,14, e entre os 50 mais utilizados, 22 têm ingredientes proibidos pela União Europeia 15.

A aplicação de agrotóxicos ganhou força principalmente a partir dos anos 1960 com o advento da chamada "revolução verde", e encontrou na vocação agrícola e grande extensão territorial do Brasil um cenário favorável para sua ampla difusão. Trata-se, portanto, de um negócio altamente lucrativo, que faturou USD 12 bilhões em 2014 16. O uso de herbicidas, inseticidas e pesticidas sempre foi alardeado pela agroindústria como a melhor alternativa para evitar a concretização da hipótese de Malthus, ou seja, só assim seriam produzidos alimentos em quantidade suficiente para alimentar uma população que crescia em progressão geométrica.
1 Universidade Federal do Maranhão, São Luís, Brasil. 2 University of Massachusetts Boston, Boston, U.S.A. 
Felizmente, a produção de alimentos contaminados não é, de forma alguma, a única solução para garantir o abastecimento de alimentos para uma população com crescente consumo e demanda alimentar 17 . Ao longo das últimas décadas, a agricultura de base ecológica tem se mostrado a melhor opção para reestruturar os atuais sistemas agroalimentares 18,19,20.

Tampouco a aplicação maciça de variedade de substâncias químicas como pesticidas, herbicidas e fungicidas garante alimentos para toda a população brasileira. A ocupação das terras agriculturáveis está cada vez mais voltada para a geração de commodities, para a fabricação de biocombustíveis e para a alimentação de animais em outros países, como a China e países membros da União Europeia 15. Como resultado da dependência da exportação de produtos primários, aliada ao desmonte de políticas de proteção social e outras políticas neoliberais, o Brasil vergonhosamente retornou ao mapa mundial da fome, de onde havia saído desde 2014 21. De acordo com a Pesquisa de Orçamentos Familiares (POF) de 2019, existiam 10,3 milhões de pessoas em situação de insegurança alimentar grave 22 em um país onde o Direito Humano à Alimentação Adequada (DHAA) é assegurado pela Constituição Federal 23.

Cabe aqui ressaltar a importância do papel do Estado como mediador entre os interesses privados e a saúde da população, em defesa dos direitos coletivos. Esse papel regulador é desempenhado pela Agência Nacional de Vigilância Sanitária (Anvisa), a quem cabe, entre outras atribuições, o controle sanitário e a responsabilidade de fiscalizar e alertar sobre os riscos associados à aplicação desses produtos 24 .

Para avaliar se os alimentos comercializados no Brasil estão de acordo com os limites de agrotóxicos permitidos pela legislação, a Anvisa implantou o Programa de Análise de Resíduos de Agrotóxicos em Alimentos (PARA) 25. As ações do PARA baseiam-se na avaliação de risco, que determina os limites de exposição considerados seguros para seres humanos, mas apresenta como limitações o fato de avaliar apenas os efeitos agudos e parte pequena das substâncias e dos alimentos produzidos no país.

Ainda assim, o artigo de Lopes \& Albuquerque 26, publicado neste fascículo de CSP com dados provenientes dos relatórios do PARA, mostra um grande percentual de amostras de alimentos com substâncias acima dos limites aceitáveis, bem como a detecção de ingredientes ativos não autorizados no país ou para uso no cultivo de determinados alimentos. Tais achados confirmam a necessidade de ampliar o debate na sociedade civil e em organizações populares, de modo a criar força política capaz de se contrapor aos interesses das corporações multinacionais e do agronegócio, e exigir alimentos de qualidade, social, econômica e ambientalmente sustentáveis para todos, de acordo com o conceito de Segurança Alimentar e Nutricional (SAN) 27.

Nesse contexto, merece destaque a informação de que a utilização de agrotóxicos está diretamente relacionada à globalização dos sistemas alimentares, acompanhada do aumento do consumo de alimentos ultraprocessados derivados da agroindústria, que têm alta densidade calórica, são ricos em químicos nocivos à saúde e fatores de risco comprovados para a obesidade e doenças crônicas. Em consonância com os dois conceitos fundamentais para os brasileiros, a SAN e o DHAA, o Guia Alimentar para a População Brasileira recomenda que a alimentação tenha como base os alimentos in natura ou minimamente processa$\operatorname{dos} 28$, o que vai de encontro do atual modelo hegemônico de produção de alimentos. Então, para cumprir o dever de promover e proteger a saúde coletiva, o governo precisa garantir a oferta de alimentos livres de contaminação por agrotóxicos para que a população tenha acesso à alimentação saudável preconizada pelo guia alimentar. Em outras palavras, 
não basta apenas estar livre da fome, é necessário que todos tenham alimentos de qualidade disponíveis e acessíveis.

O artigo descreve o PARA como um instrumento importante para auxiliar as inspeções sanitárias e dar visibilidade ao uso abusivo dos agrotóxicos no Brasil, apesar de não representar a real situação destes resíduos nos alimentos produzidos no país. Questiona, por exemplo, as limitações dos métodos empregados para a adoção de parâmetros que estabelecem os limites máximos de resíduos permitidos para os alimentos e como estes limites são muito mais tolerantes do que os estabelecidos na União Europeia, ao mesmo tempo em que expõe os interesses econômicos envolvidos no uso dos agrotóxicos no Brasil.

Conforme as recomendações do Dossiê Abrasco: Um Alerta sobre os Impactos dos Agrotóxicos na Saúde 15, é preciso fortalecer e ampliar o PARA, incluindo na avaliação outros alimentos in natura, alimentos processados, água e carnes. O documento recomenda também banir os agrotóxicos proibidos em outros países porque já são considerados como um risco inaceitável à saúde humana e ao meio ambiente. Porém, como é possível conseguir avanços, incluindo a conscientização da sociedade sobre as consequências do uso abusivo dos agrotóxicos, ou dar visibilidade às experiências bem-sucedidas baseadas em modos sustentáveis de produção de alimentos, quando vivemos o desmonte das políticas públicas e o ataque constante à sociedade civil pelo atual governo brasileiro?

A publicação de dados resultantes de estudos científicos, como os apresentados no artigo de Lopes \& Albuquerque, reafirma o papel da ciência socialmente comprometida com a produção de conhecimento que dê resposta aos problemas enfrentados pela população. Essa atuação é especialmente relevante porque parte desses problemas advém de uma proposital negação de sua existência por parte das empresas produtoras, a quem interessa que permaneçam ocultos em nome dos seus lucros financeiros. A divulgação de resultados de tais estudos pode e deve estimular o debate na comunidade acadêmica e nos movimentos sociais sobre questões antigas e ainda não resolvidas, contribuindo para a elaboração de políticas públicas que promovam a saúde, previnam doenças evitáveis, em prol de uma sociedade mais justa e democrática. 


\section{Colaboradores}

M. T. B. A. Frota redigiu o texto. C. E. Siqueira colaborou na redação e revisou o texto.

\section{Informações adicionais}

ORCID: Maria Tereza Borges Araujo Frota (00000001-6889-5785); Carlos Eduardo Siqueira (00000001-8993-3031).
1. Rigotto RM, Vasconcelos DP, Rocha MM. Pesticide use in Brazil and problems for public health. Cad Saúde Pública 2014; 30:1360-62.

2. Associação Brasileira de Saúde Coletiva. Dossiê ABRASCO: um alerta sobre os impactos dos agrotóxicos na saúde. Rio de Janeiro: Associação Brasileira de Saúde Coletiva; 2012.

3. Dutra RMS, Souza MMOJH. Impactos negativos do uso de agrotóxicos à saúde humana. Hygeia (Uberlândia) 2017; 13:127-40.

4. Burillo-Putze G, Luzardo OP, García CP, Zumbado M, Yanes C, Trujillo-Martin M, et al. Exposure to persistent and non-persistent pesticides in a non-occupationally exposed population in Tenerife Island (Spain). Gac Sanit 2014; 28:301-4.

5. Lopes CVA, Albuquerque GSC. Agrotóxicos e seus impactos na saúde humana e ambiental: uma revisão sistemática. Saúde Debate 2018; 42:518-34.

6. Bortolotto CC, Hirschmann R, Martins-Silva T, Facchini LA. Exposição a agrotóxicos: estudo de base populacional em zona rural do sul do Brasil. Rev Bras Epidemiol 2020; 23:e200027.

7. Viero CM, Camponogara S, Cezar-Vaz MR, Costa VZ, Beck CLC. Sociedade de risco: o uso dos agrotóxicos e implicações na saúde do trabalhador rural. Esc Anna Nery Rev Enferm 2016; 20:99-105.

8. Murakami Y, Pinto NF, Albuquerque GSC, Perna PO, Lacerda A. Intoxicação crônica por agrotóxicos em fumicultores. Saúde Debate 2017; 41:563-76.

9. Menck VF, Cossella KG, Oliveira JM. Resíduos de agrotóxicos no leite humano e seus impactos na saúde materno-infantil: resultados de estudos brasileiros. Segurança Alimentar e Nutricional 2015; 22:608-17.
10. Galo Netto C. Nem o leite materno escapa da contaminação. Jornal da Unicamp 2009; 23 mar. http://www.unicamp.br/unicamp/uni camp_hoje/ju/marco2009/ju423pdf/Pag04. pdf.

11. Lara SS, Pignati WA, Pignatti MG, Leão LHC, Machado JHM. A agricultura do agronegócio e sua relação com a intoxicação aguda por agrotóxicos no Brasil. Hygeia (Uberlândia) 2019; 15:1-19.

12. Belchior DCV, de Souza Saraiva A, López AMC, Scheidt GN. Impactos de agrotóxicos sobre o meio ambiente e a saúde humana. Cadernos de Ciência \& Tecnologia 2017; 34:13551.

13. Ministério da Agricultura, Pecuária e Abastecimento. Ato no 82, de 25 de novembro de 2019. Diário Oficial da União 2019; 27 nov.

14. Ministério da Agricultura, Pecuária e Abastecimento. Ato no 91, de 26 de dezembro de 2019. Diário Oficial da União 2019; 27 dez.

15. Carneiro FF, Rigotto RM, Augusto LGS, Friedrich K, Búrigo AC, organizadores. Dossiê ABRASCO: um alerta sobre os impactos dos agrotóxicos na saúde. São Paulo: Expressão Popular/Rio de Janeiro: Escola Politécnica de Saúde Joaquim Venâncio, Fundação Oswaldo Cruz; 2015.

16. Associação Brasileira dos Defensivos Pós-Patente. As 20 maiores empresas agroquímicas brasileiras em 2017. https://www.aenda.org. $\mathrm{br} /$ noticia_imprensa/as-20-maiores-empre sas-agroquimicas-brasileiras-em-2017/ (acessado em 20/Jan/2021).

17. Badgley C, Moghtader J, Quintero E, Zakem E, Chappell M, Avilés-Vázquez K, et al. Organic agriculture and the global food supply. Renewable Agriculture and Food Systems 2007; 22:86-108. 
18. McIntyre BD, Herren HR, Wakhungu J, Watson RT, editors. Agriculture at a crossroads: global report. Washington DC: International Assessment of Agricultural Knowledge, Science and Technology for Development; 2009.

19. United Nations Conference on Trade and Development. Trade and environment review 2013. Wake up before it is too late: make agriculture truly sustainable now for food security in a changing climate. New York: United Nations; 2013.

20. De Schutter O. Agroecology and the right to food. http://www.srfood.org/es/agroecologia (acessado em 02/Jan/2021)

21. Organização das Nações Unidas para Agricultura e Alimentação. O estado da segurança alimentar e nutricional no Brasil: um retrato multidimensional. Relatório 2014. Brasília: Organização das Nações Unidas para Agricultura e Alimentação; 2014.

22. Instituto Brasileiro de Geografia e Estatística. Pesquisa de Orçamentos Familiares 20172018: primeiros resultados. Rio de Janeiro: Instituto Brasileiro de Geografia e Estatística; 2019

23. Brasil. Emenda Constitucional no 64, de 4 de fevereiro de 2010. Altera o art. 6o da Constituição Federal, para introduzir a alimentação como direito social. Diário Oficial da União 2010; 4 fev.
24. Brasil. Lei no 9782, de 26 de janeiro de 1999. Define o Sistema Nacional de Vigilância Sanitária, cria a Agência Nacional de Vigilância Sanitária, e dá outras providências. Diário Oficial da União 1999; 27 jan.

25. Agência Nacional de Vigilância Sanitária. Resolução de Diretoria Colegiada no 119 , de 19 de maio de 2003. Diário Oficial da União 2003; 22 mai.

26. Lopes CVA, Albuquerque GSC. Desafios e avanços no controle de resíduos de agrotóxicos no Brasil: 15 anos do Programa de Análise de Resíduos de Agrotóxicos em Alimentos. Cad Saúde Pública 2021; 37:e00116219.

27. Brasil. Lei no 11.346 , de 15 de setembro de 2006. Cria o Sistema Nacional de Segurança Alimentar e Nutricional - SISAN com vistas em assegurar o direito humano à alimentação adequada e dá outras providências. Diário Oficial da União 2006; 18 set.

28. Ministério da Saúde. Guia alimentar para a população brasileira. Brasília: Ministério da Saúde; 2014 